\title{
Diretrizes para desenvolvimento coletivo de melhoria contínua em arranjos produtivos locais
}

\section{Guidelines for collective development of continuous improvement in local productive arrangements}

\author{
Ariana Martins Vieira ${ }^{1}$ \\ Edwin Vladimir Cardoza Galdamez ${ }^{2}$ \\ Fernando Bernardi de Souza ${ }^{3}$ \\ Otávio José de Oliveira ${ }^{3}$
}

\begin{abstract}
Resumo: Em um cenário dinâmico e competitivo como o atual, a melhoria contínua passou a ser um requisito básico da gestão que visa potencializar o desempenho de empresas e dos possíveis Arranjos Produtivos Locais em que estejam inseridas, sobretudo no caso daquelas de menor porte. O objetivo deste trabalho é apresentar diretrizes para desenvolvimento coletivo de melhoria contínua em Micro, Pequenas e Médias Empresas industriais que atuem neste tipo de arranjo. A proposta foi desenvolvida a partir do referencial teórico e validada por um estudo de caso. As diretrizes estão estruturadas em seis etapas principais: Preparação, Diagnóstico do Arranjo, Diagnóstico das empresas, Implantação, Auditoria e Avaliação.
\end{abstract}

Palavras-chave: Melhoria contínua. Gestão da qualidade. Micro, pequenas e médias empresas. Arranjo produtivo local. Setor industrial.

\begin{abstract}
In the current dynamic and competitive environment, continuous improvement has become a basic management requirement aiming to increase performance of firms and local productive arrangements. The objective of this study is to present guidelines for collective development of continuous improvement in Micro, Small, and Medium Enterprises that operate in this type of arrangement. The proposal was formulated based on the theoretical concept and validated by a case study. The guidelines are composed of six main stages: Preparation, Array Diagnosis, Company Diagnostics, Implementation, Audit, and Evaluation.
\end{abstract}

Keywords: Continuous improvement. Quality management. Micro. Small and medium enterprises. Local productive arrangement. Industrial sector.

\section{Introdução}

A internacionalização da economia, os avanços tecnológicos, as mudanças do mercado e dos sistemas de produção criaram um novo ambiente competitivo. Nele, para as Micro, Pequenas e Médias Empresas (MPMEs), as exigências mercadológicas (produtos e serviços com qualidade), econômicas (redução de impostos e tributos), ambientais (redução de resíduos) e sociais (recursos humanos qualificados e assistência à comunidade do entorno) são ainda mais difíceis de atingir por possuírem, em geral, menos recursos financeiros e materiais, mão de obra menos qualificada e menor expertise em gestão que seus concorrentes de maior porte (OLIVEIRA, 2006).
Uma estratégia para estas empresas se fortalecerem competitivamente consiste em organizarem-se em Arranjos Produtivos Locais (APLs), cujo objetivo é o desenvolvimento coletivo a partir do esforço conjunto de empresários/empresas, instituições de ensino e financeiras e do governo local. Os APLs desempenham um importante papel para as MPMEs, possibilitando que se complementem, aumentem a capacidade produtiva, as oportunidades de sobrevivência e seu crescimento, além de contribuírem para o desenvolvimento local e regional (VIEIRA, 2011).

Estes aspectos estimulam e favorecem o desenvolvimento estruturado de processos de melhoria

\footnotetext{
${ }^{1}$ Departamento de Engenharia Têxtil, Universidade Estadual de Maringá - UEM, Av. Colombo, 5790, Jd. Universitário, CEP 87020-900, Maringá, PR, Brasil, e-mail: arianamvi@yahoo.com.br

2 Departamento de Engenharia de Produção, Universidade Estadual de Maringá - UEM, Av. Colombo, 5790, Jd. Universitário, CEP 87020-900, Maringá, PR, Brasil, email: evcgaldamez@uem.br

${ }^{3}$ Departamento de Produção, Faculdade de Engenharia de Guaratinguetá - FEG, Universidade Estadual Paulista "Júlio de Mesquita Filho" - UNESP. Av. Ariberto Pereira da Cunha, 333, CEP 12516-410, Guaratinguetá, SP, Brasil, e-mail: otaviodeoliveira@uol.com.br Recebido em 31/5/2012 — Aceito em 28/8/2012
}

Suporte financeiro: CNPq e à Fundação Araucária. 
contínua e mudanças na gestão empresarial com foco na qualidade dos produtos e processos, tanto na esfera das empresas como do APL como um todo.

As empresas de menor porte enfrentam diversas barreiras se comparadas às maiores, que, em geral, estão relacionadas ao ambiente competitivo e organizacional, à gestão empresarial e, em particular, à melhoria contínua, uma vez que são mais vulneráveis às contingências mercadológicas e econômicas e possuem menos recursos para se protegerem. Assim, estas empresas quando organizadas em APLs desenvolvem mecanismos para encontrar soluções gerenciais que sozinhas não conseguiriam (BUENO, 2006).

Esforços públicos e de agentes locais devem ser realizados para melhorar os sistemas de competição e produção da indústria. Um dos principais desafios para a comunidade científica e governamental é criar mecanismos organizacionais que promovam o desenvolvimento sustentável de um local, região ou país e os APLs são uma interessante e eficaz alternativa para isto (GALDAMEZ, 2007).

Políticas de fomento a empresas de menor porte são mais efetivas quando elas estão organizadas em grupo, pois, neste caso, o potencial competitivo advém não de ganhos de escala individuais, mas dos ganhos decorrentes de maior cooperação entre elas (BRASIL, 2004).

A questão de pesquisa que norteou o desenvolvimento deste trabalho foi a seguinte: de que forma a melhoria contínua poderia ser desenvolvida de forma coletiva em Micro, Pequenas e Médias Empresas inseridas em Arranjos Produtivos Locais para gerar incremento competitivo?

Portanto, este estudo tem como objetivo propor diretrizes para o desenvolvimento coletivo de processos de melhoria contínua em MPMEs industriais que atuem em APLs. A proposta foi desenvolvida com base no referencial teórico e validada a partir das práticas e necessidades concernentes a este tema, verificadas em um estudo de caso num APL de confecção.

Depois desta introdução é apresentada uma síntese da revisão bibliográfica utilizada para realização da pesquisa, que contempla os seguintes temas: gestão da qualidade, melhoria contínua e arranjo produtivo local. Na sequência, é apresentado o método de pesquisa seguido do estudo de caso em um APL, com finalidade de validação da proposta. Por fim, têm-se a proposta de diretrizes para desenvolvimento coletivo de processos de melhoria contínua em MPMEs que atuem em APLs, a conclusão e as referências bibliográficas utilizadas no artigo.

\section{Gestão da qualidade}

A gestão da qualidade é cada vez mais adotada pelos gestores como forma de atingir os objetivos das organizações (PALADINI, 2004). Ela possibilita a obtenção do comprometimento de todos com a excelência em processos, produtos e serviços, priorizando seu aprimoramento contínuo (OLIVEIRA, 2004).

Gestão da qualidade é um conjunto de práticas desenvolvidas em organizações de todos os tipos, baseadas nas necessidades de clientes internos e externos, no melhoramento contínuo e no trabalho dos times da qualidade, que visa aprimorar processos, produtos e serviços (ZU, 2009).

Depexe e Paladini (2008) classificam os benefícios da gestão qualidade em internos (relacionados aos recursos humanos e aos aspectos operacionais) e externos (relacionados aos clientes e aos aspectos financeiros).

Como internos destacam-se: melhoria na definição e padronização dos procedimentos de trabalho; melhoria na definição das responsabilidades dos funcionários; aumento da confiança da empresa na qualidade; aumento do comprometimento e satisfação dos funcionários com o trabalho; redução de improviso por meio da melhoria dos procedimentos e melhoria na comunicação entre a gerência e os funcionários.

Já em relação aos externos, destacam-se: melhor resposta aos requisitos dos clientes; abertura de novos mercados; melhoria nas relações com os consumidores; aumento da satisfação dos clientes; queda no número de reclamações; retenção de clientes e aumento da participação em mercados (DEPEXE; PALADINI, 2008).

Torelli e Ferreira (1995) sugerem um modelo genérico para desenvolvimento de Sistemas de Gestão Qualidade (SGQs) em organizações. Ele deve ser adaptado à realidade de cada empresa, ou seja, considerar seu mercado, fornecedores, processos, produtos, funcionários e sua cultura. Ele compreende as seguintes fases:

- Fase Zero - primeiros contatos: os recursos humanos devem ter contato com informações sobre o sistema a ser implantado por meio de palestras, seminários, estudos de casos, entre outros;

- Fase 1 - capacitação nas metodologias envolvidas: seleciona-se o grupo que deve liderar as mudanças na empresa para treinar e conscientizar os demais;

- Fase 2 - identificação de clientes externos: identificação e compreensão das principais características e necessidades dos clientes externos;

- Fase 3 - identificação do sistema atual: o objetivo desta fase é que o grupo de implantação tenha conhecimento sobre os processos e recursos existentes na empresa, determinação da capacidade instalada, mapeamento dos fluxos de informação e cultura organizacional;

- Fase 4-avaliação do sistema: com base nos dados coletados na fase anterior, o grupo de implantação 
deverá fazer uma avaliação sobre a situação vigente em todos os níveis da organização;

- Fase 5 - difusão: difusão dos procedimentos de implantação e seus objetivos;

- Fase 6 - operacionalização: inserção do "elemento" qualidade no plano estratégico da organização e diluição por toda a organização;

- Fase 7-aprimoramento: todos os processos e funções devem estar perfeitamente descritos e documentados para que possam ser aplicados e melhorados continuamente; e

- Fase 8 - auditoria: objetiva estabelecer e manter o sistema de qualidade funcionando em conformidade com o planejamento.

Estas fases foram as referências mais utilizadas no estudo que contribuiu intensamente para a elaboração das diretrizes aqui propostas.

No entanto, segundo Rodrigues (1998), algumas empresas trabalham com a gestão da qualidade sem a devida consideração da cultura organizacional, o que afeta negativamente o seu desempenho e dificulta a obtenção dos benefícios que poderiam advir. A gestão e cultura são simultaneamente causa e efeito das inter-relações dinâmicas que ocorrem entre si nos diversos setores e ambientes da organização. Este processo deve respeitar as condições sistêmicas que a envolvem, como suas características estruturais e humanas, o seu ambiente e os anseios dos profissionais (SANTOS, 1998; OBADIA; VIDAL; MELO, 2007).

O bom desempenho de um sistema da qualidade depende do comprometimento do fator humano, ou seja, da qualificação, do treinamento e da motivação dos envolvidos com a implementação das novas práticas (SILVA, 2003).

A resistência é um dos entraves comuns no desenvolvimento de práticas de gestão relacionadas à qualidade, que pode ser superada desde que as pessoas sejam educadas e preparadas antecipadamente para as mudanças. O processo de educação e comunicação pode envolver reuniões, apresentações, treinamentos, relatórios e outros meios de comunicar a necessidade de mudança (JACOBSEN; RODRIGUES, 2002; SANTOS, 2005; PINHEIRO, 2009).

A gestão da qualidade e a melhoria contínua são operacionalizadas principalmente por meio das ferramentas da qualidade. Dentre as quais se destacam: Sete Ferramentas Básicas (Folha de Verificação, Gráfico de Pareto, Diagrama de Causa e Efeito, Estratificação, Histograma, Diagrama de Dispersão e Gráfico de Controle); Desdobramento da Função Qualidade; Análise do Modo e Efeito de Falhas; 5W1H; Brainstorming; Programa 5S; e Círculos de Controle da qualidade (OSBORN, 1991; SCHOLTES, 1992; KATZENBACH; SMITH, 1993; MIGUEL, 2001; FERNANDES; REBELATO, 2006; CARNEVALLI; MIGUEL, 2007; AMURA;
CUPERSCHMID; PEREIRA, 2008; GAPP; FISHER; KOBAYASHI, 2008; NUNES; ALVES, 2008; SOUSA; CAMPOS; RAMOS, 2008; LIN; LUH, 2009; OLIVEIRA, 2009).

\section{Melhoria contínua}

A melhoria contínua é um elemento essencial às práticas da qualidade, que pode ser desenvolvida isoladamente e com seu fim próprio ou como base de um programa da qualidade mais complexo, tais como ISO 9001 e Seis Sigmas. A melhoria contínua objetiva evoluir sistematicamente projetos, processos, produtos e serviços, superando obstáculos, solucionando problemas, aprendendo com erros e acertos, ensinando, conhecendo, compartilhando e contribuindo tanto para o crescimento do indivíduo como da organização (BESSANT; CAFFYN; GALLAGHER, 2001; MESQUITA; ALLIPRANDINI, 2003; JAGER et al., 2004; MARTINS; LAUGENI, 2005).

Bessant, Caffyn e Gallagher (2001) classificam o estágio de evolução da melhoria contínua em cinco níveis, conforme Quadro 1.Estes últimos autores destacam que cada nível está associado ao desenvolvimento de rotinas de comportamentos e habilidades voltados para a melhoria contínua. Esta classificação pode ajudar as empresas a compreenderem em que estágio se encontram, onde estão em relação a outras e como podem desenvolver um plano para evoluírem.

De acordo com Carpinetti (2005), os programas de qualidade são bastante difundidos e aplicados nas grandes empresas, o que não acontece nas menores, uma vez que carecem de capacitação e possuem várias limitações (falta de recursos, baixa qualificação da mão de obra, restrições de mercado e fornecedores, entre outras), dificultando iniciativas voltadas ao sistema de produção, ao desenvolvimento de produtos, custos e meio ambiente. Enxerga-se aí, portanto, uma grande oportunidade para desenvolvimento de uma proposta para introdução de práticas de melhoria contínua e gestão da qualidade em micro, pequenas e médias empresas.

Alguns trabalhos subsidiaram mais fortemente a formulação da proposta apresentada neste trabalho, dentre as quais se destacam as de Gerolamo (2003), Simões e Alliprandini (2006) e Zampini e Toledo (2008).

Gerolamo (2003) adapta o ciclo PDCA para ser utilizado no gerenciamento da melhoria e mudança de desempenho organizacional, conforme se segue:

- Etapa P (plan): identificar e analisar as estratégias emergentes e planejar as estratégias futuras. Este processo de formulação da estratégia deverá ser revisto continuamente; 
Quadro 1. Níveis de evolução da melhoria contínua.

\begin{tabular}{|l|l|}
\hline Níveis de melhoria contínua & \multicolumn{1}{c|}{ Comportamentos característicos } \\
\hline 1. Pré-melhoria contínua & $\begin{array}{l}\text { Os problemas são resolvidos de forma aleatória e pontual com soluções de curto } \\
\text { prazo. Os gestores não visualizam a melhoria contínua como um processo. }\end{array}$ \\
\hline 2. melhoria contínua estruturada & $\begin{array}{l}\text { Há comprometimento formal na construção de um sistema que irá desenvolver } \\
\text { a melhoria contínua. O sistema ocorre por meio da utilização de treinamentos } \\
\text { e ferramentas voltadas à melhoria contínua e da medição das atividades } \\
\text { de desempenho. Contudo, observam-se efeitos mínimos e localizados no } \\
\text { desempenho da empresa. }\end{array}$ \\
\hline 3. Melhoria contínua orientada & $\begin{array}{l}\text { Níveis 1 e 2 adicionando uma ligação dos procedimentos de melhoria contínua } \\
\text { aos objetivos estratégicos. Existe o desdobramento das diretrizes e medições do } \\
\text { desempenho ligadas formalmente à estratégia. }\end{array}$ \\
\hline 4. Melhoria contínua pró-ativa & $\begin{array}{l}\text { Níveis 1,2 e 3 somando a preocupação em direcionar responsabilidades para } \\
\text { resolução de problemas em toda a empresa de forma sistemática. Existe um alto } \\
\text { nível de experiência na resolução de problemas. }\end{array}$ \\
\hline $\begin{array}{l}\text { 5. Capacidade total de melhoria } \\
\text { contínua }\end{array}$ & $\begin{array}{l}\text { Todos os níveis anteriores adicionando uma aproximação em relação ao modelo } \\
\text { de aprendizado organizacional. A melhoria contínua é base para a sobrevivência } \\
\text { da organização e está integrada à sua rotina. }\end{array}$ \\
\hline
\end{tabular}

Fonte: Bessant, Caffyn e Gallagher (2001).

- Etapa D (do): com o direcionamento estratégico, pode-se partir para a identificação e implementação das ações de melhoria e mudança;

- Etapa C (check): após a execução, deve-se avaliar, verificar os resultados e dar o feedback necessário, comparando os resultados com as estratégias atuais e futuras; $\mathrm{e}$

- Etapa A (act): documentar as lições aprendidas pelas ações implementadas e consolidar a melhoria e mudança adquirida.

Complementando, segundo Caffyn (1999), implementar um programa de melhoria contínua nas empresas pode seguir um processo interativo como do ciclo PDCA. A primeira etapa seria analisar a situação atual e, em seguida, analisar o efeito das alterações efetuadas e seus impactos nos processos de negócio, tais como: o progresso da melhoria contínua (ou a falta dela), o impacto das intervenções e das restrições. Desta forma, será possível identificar áreas que necessitam de maior apoio, desenvolver novos planos de atuação e identificar exemplos de boas práticas.

Simões e Alliprandini (2006) propõem um modelo de boas práticas para gestão da melhoria contínua. $\mathrm{O}$ modelo tem como propósito a interação e coordenação das atividades da produção de forma integrada e está estruturado em quatro fases:

- Fase 1-planejamento: fase em que se estuda e define o planejamento estratégico, a concorrência, o cliente e a comunicação;

- Fase 2 - ехесис̧ão: fase em que se colocam em prática as atividades definidas na fase $1 \mathrm{e}$, para isso, os processos precisam estar definidos;
- Fase 3 - medição: fase em que se realiza a medição das atividades de melhoria planejadas por meio de indicadores de desempenho, apresentando os resultados das atividades de melhoria contínua definidas nas fases 1 e 2 ; e

- Fase 4-auditoria e ações: fase em que se atua na ação por meio de auditorias internas.

Zampini e Toledo (2008) propõem um modelo constituído por quatro etapas para a estruturação de programas de melhoria contínua. $\mathrm{O}$ objetivo do modelo é integrar a gestão da melhoria contínua com as estratégias de negócio de forma sistemática.

A primeira etapa diz respeito a formalizar o processo, segundo o qual a gestão da melhoria contínua deve identificar objetivos, responsáveis, estrutura, padronização e formalização.

A segunda etapa envolve a análise da situação atual e a identificação de problemas e oportunidades de melhorias, definindo objetivos, indicadores e plano de ação.

A terceira etapa visa criar um ambiente de motivação para as práticas da melhoria contínua, que deverá estar alinhado com as mudanças de comportamento e proporcionar uma cultura voltada para a melhoria.

Por fim, a quarta etapa objetiva desenvolver capacidade e maturidade. Para isso, deve-se identificar o estágio de melhoria contínua no qual a empresa se encontra com o intuito de analisar o nível da capacitação complementar ainda necessária para os colaboradores.

Com base principalmente nestas referências e propostas e considerando sempre as características do ambiente dos arranjos produtivos locais, cuja definição e principais particularidades serão apresentadas 
a seguir, é que foram desenvolvidas as diretrizes apresentadas neste trabalho.

\section{Arranjo produtivo local}

Arranjo Produtivo Local (APL) pode ser definido como um agrupamento geograficamente concentrado de empresas inter-relacionadas e instituições correlatas em uma determinada área, vinculadas por elementos comuns e complementares, acrescentando efeitos distributivos em termos patrimoniais e de emprego às dimensões setoriais e regionais (PORTER, 1999).

A essência de um APL reside nas questões relacionadas com o desenvolvimento local e os diversos agentes envolvidos: organizações produtivas, instituições públicas e de fomento (prefeituras, governo e instituições de apoio), universidades e institutos de pesquisa. Quanto mais eficiente for a integração e o envolvimento desses agentes, melhores serão os seus resultados (BUENO, 2006). Para Zaccarelli (2000), se o agrupamento de empresas não tiver um relacionamento que permita formar um conjunto com características competitivas, ele não constituirá um APL.

Conforme Cassiolato e Lastres (2003), a cooperação empresarial pode ocorrer por meio de:

- Intercâmbio sistemático de informações produtivas, tecnológicas e mercadológicas (com clientes, fornecedores, concorrentes, entre outros);

- Interação de vários tipos, envolvendo empresas e outras organizações, por meio de programas comuns de treinamento, realização de feiras, cursos e seminários; $\mathrm{e}$

- Integração de competências, por meio da realização de projetos conjuntos, desde a melhoria de produtos e processos até sua pesquisa e desenvolvimento. Um exemplo de cooperação de competências é a criação da marca ou selo que identifique o produto que se origina de um determinado arranjo.

Aglomerações atraem compradores e podem facilitar o acesso aos mercados distantes. Algumas vezes produtores podem simplesmente usar os canais de mercados que surgem (economias externas), outras vezes necessitam tomar ações em conjunto, como, por exemplo, organizar uma feira de negócios ou a certificação de seus produtos. A soma dessas economias externas e de ações conjuntas resulta no desenvolvimento de eficiência coletiva (vantagem competitiva) (SCHMITZ, 1995).

O desenvolvimento de práticas de melhoria contínua em empresas de pequeno porte pode se dar a partir da cooperação e coordenação de ações conjuntas, que podem ser estruturadas pela governança local em APLs.
A governança constitui-se do envolvimento conjunto de diversos atores nas atividades coletivas e de suas ações de coordenação. Suas atividades incluem a identificação de problemas conjuntos, proposições de soluções e a elaboração de estratégias para melhoria de processos, produtos e serviços, aumentando a competitividade do grupo (tais como programas de melhoria contínua, gestão da qualidade, gestão estratégica, entre outras) (STORPER; HARRISON, 1991; KARAEV; KOH; SZAMOSI, 2007).

Esta forma de organização permite que as MPMEs se incorporem em uma rede, e assim possam promover um ciclo de melhoria contínua. A cooperação pode promover a evolução das MPMEs com frequentes mudanças e reposicionamentos competitivos das atividades industriais na cadeia de valor, permitindo que elas expandam seus mercados (BELUSSI; ARCANGELI, 1998).

Para Suzigan, Garcia e Furtado (2007), por governança em APLs, entende-se a capacidade de comando ou coordenação que certos agentes (empresas, instituições ou mesmo um agente coordenador) exercem sobre as inter-relações produtivas, comerciais e tecnológicas, influenciando decisivamente o desenvolvimento do arranjo local. Neste sentido, as instituições vinculadas aos APLs, juntamente com os empresários, dão forma à estrutura de governança com as particularidades de cada região e segmento de atuação.

Conforme Amato Neto (2009), algumas das principais ações de cooperação fomentadas pela governança podem ser:

- Compras conjuntas;

- Participação conjunta em feiras e exposições (nacionais e internacionais);

- Estratégias compartilhadas de comercialização (marca, propaganda, canais de distribuição, força de vendas, entre outras);

- Compartilhamento de instalações como unidades de manufatura e laboratórios de testes;

- Realização de serviços conjuntos;

- Participação em consórcios de exportação; e

- Estabelecimento conjunto de escolas técnicas e centros de pesquisa para formação e qualificação da mão de obra.

O sucesso e o desenvolvimento dos arranjos produtivos têm forte relação com os aspectos subjetivos, tais como a motivação e o comprometimento dos atores envolvidos. Para intensificar os relacionamentos, é necessário consolidar os elos de confiança entre os atores de governança (VILLELA; PINTO, 2009).

\section{Método de pesquisa}

A elaboração das diretrizes para desenvolvimento coletivo de melhoria contínua em MPMEs inseridas 
em APLs, objetivo deste artigo, foi alicerçada em dois elementos principais: 1) contribuições da literatura científica, sintetizada nos itens anteriores deste trabalho; e 2) investigação na forma de estudo de caso realizado no APL do setor de confecção de Maringá/Cianorte, cujo objetivo foi proporcionar aos pesquisadores um contato real com o ambiente de um APL e o contato direto com um projeto de desenvolvimento de melhoria contínua, de forma que as diretrizes propostas ganhassem um caráter mais aplicável às reais macrocaracterísticas e realidade do tipo de cenário em que poderão ser implementadas: APLs.

Estudo de caso é o estudo minucioso de um fenômeno em que se devem utilizar mais de uma fonte de evidência para coleta de informações, sendo indicado para responder questões do tipo "como" e "porque" (HYDE, 2000; MIGUEL, 2007; YIN, 2010). No caso deste trabalho, foram feitas visitas in loco, entrevistas semiestruturadas com representantes da governança e com alguns proprietários de empresas e análise de documentos relativos aos processos de gestão do APL.

A escolha do referido APL para estudo se deu principalmente com base nos seguintes critérios: potencial de contribuição para o estudo em função do grande porte e da complexidade de seus processos de gestão; concordância da governança e empresários em colaborar com este estudo; existência de relacionamento anterior do grupo destes autores/ pesquisadores com o APL, o que facilitou o acesso a informações e, principalmente, pela possibilidade de acompanhar o desenvolvimento de um projeto de melhoria contínua, que também serviu intensamente como base para a formulação da proposta apresentada neste artigo.

Quando da realização do estudo de caso a revisão do referencial teórico já tinha sido realizada e uma versão prévia das diretrizes já tinha sido elaborada. Portanto, ele serviu também como objeto de seu aprimoramento e validação.

O referencial teórico foi estruturado visando contemplar os principais elementos constantes do escopo da pesquisa de forma a dar suporte a sua realização. Para sua confecção, utilizaram-se principalmente as seguintes bases de dados: Emerald, Direct Science, Scielo, ProQuest, Portal de periódicos da CAPES, sites de teses e dissertações das principais Universidades brasileiras e dos principais congressos da área de Engenharia de Produção.

$\mathrm{O}$ estudo de caso foi realizado no APL do setor de confecção de Maringá/Cianorte. Trata-se de um complexo industrial formado por aproximadamente 1.700 Micro, Pequenas e Médias Empresas formais que atuam nas atividades de vestuário, uniformes, bonés e serviços de acabamento, gerando em torno de 60 mil empregos diretos e 75 mil indiretos (DAIBERT; FISCHER, 2008; SINDICATO..., 2009; REDE..., 2010).
O objetivo do estudo de caso foi auxiliar no desenvolvimento da proposta de diretrizes para desenvolvimento coletivo de melhoria contínua com dados extraídos da realidade das MPMEs e do APL pesquisado. Com a experiência acumulada devido ao acesso a algumas características e práticas do APL, pôde-se fortalecer o grau de aplicabilidade da proposta.

Mais especificamente, as principais funções do caso foram: $i$ ) ambientar os pesquisadores com a realidade de um APL para dotar as diretrizes de caráter mais aplicável; ii) identificar boas práticas e principais dificuldades da gestão do APL e das práticas de melhoria contínua; iii) acompanhar de perto, identificando elementos reais de contribuição às diretrizes aqui apresentadas, o desenvolvimento e implantação de uma proposta de melhoria contínua para um APL; e $i v$ ) validar as diretrizes propostas neste trabalho a partir do refinamento, adaptação e/ou inclusão de novos elementos.

\section{Estudo de caso}

$\mathrm{O}$ estudo de caso foi realizado durante o desenvolvimento de um projeto de extensão tecnológica empresarial do Programa Universidade sem Fronteiras financiado pela Fundação Araucária e Secretaria de Ciência e Tecnologia do Estado do Paraná no referido APL, que tinha como finalidade o desenvolvimento de processos coletivos de melhoria contínua. As fases desenvolvidas estão ilustradas na Figura 1.

O desenvolvimento do projeto contemplou quatro fases, subdivididas em atividades, conforme Figura 1, e sucintamente relatadas a seguir:

\subsection{Fase 1 - Planejamento e formação da equipe de melhoria contínua do APL}

Esta fase foi dividida em quatro atividades. A primeira consistiu na formação do grupo de cooperação empresarial (atores locais), cujo objetivo foi viabilizar o desenvolvimento do projeto, buscando-se inicialmente parceiros que pudessem colaborar com conhecimento técnico, recursos financeiros e facilitar a integração da universidade com as empresas.

$\mathrm{Na}$ segunda atividade, formação do grupo de cooperação científica, houve a integração de duas instituições de pesquisa. As experiências dos pesquisadores foram utilizadas como base para o desenvolvimento, implantação e acompanhamento do projeto.

Em seguida, houve a formação da equipe técnica para implantação dos processos de melhoria contínua, ou seja, a seleção da equipe de implantação da proposta de melhoria contínua nas empresas pertencentes ao APL. A equipe foi formada por duas profissionais recém-formadas em engenharia de produção, quatro estudantes de graduação de engenharia de produção e uma de administração. 


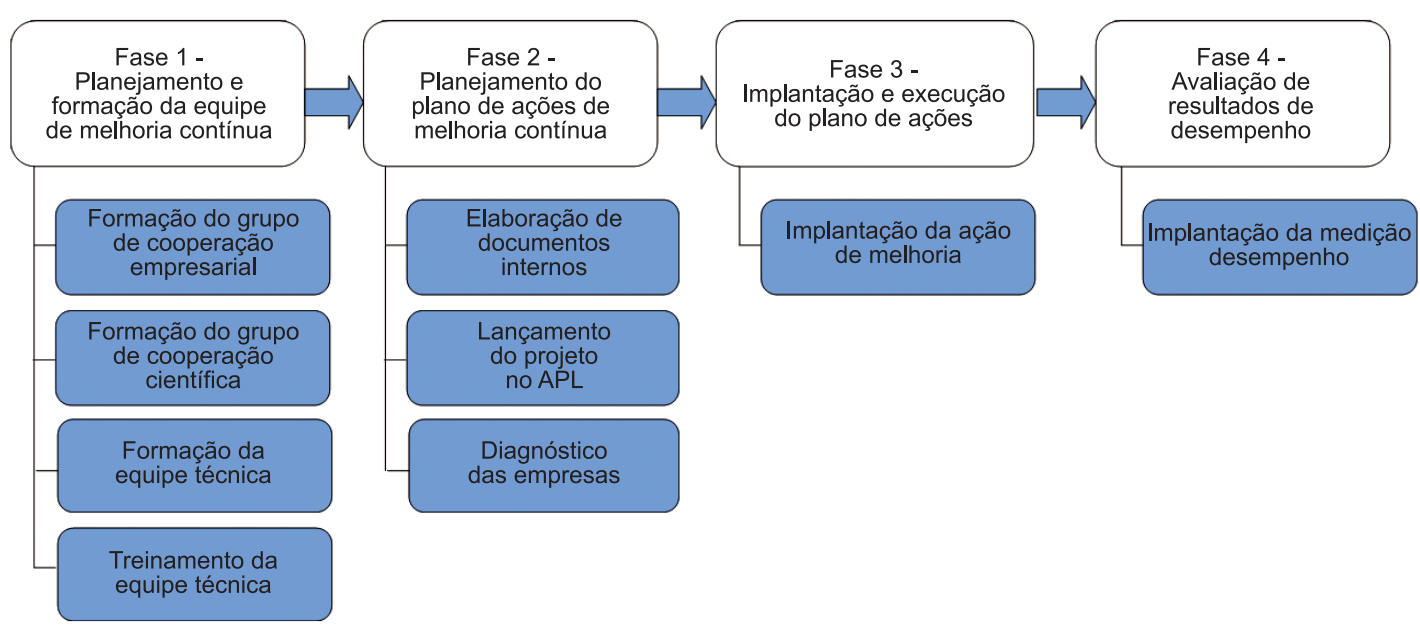

Figura 1. Fases de implantação de melhoria contínua.

A última atividade da primeira fase do projeto foi o treinamento da equipe técnica que consistiu da capacitação interna durante nove seminários, que variaram de 2 a 4 horas, conforme a necessidade.

\subsection{Fase 2 - Planejamento do plano de ações de melhoria contínua}

Esta fase foi dividida em três atividades: elaboração de documentos internos, lançamento do projeto no APL e diagnóstico empresarial.

$\mathrm{Na}$ atividade de elaboração de documentos internos, foram desenvolvidos, pela equipe técnica e professores, modelos de documentos utilizados durante a implantação e acompanhamento nas empresas, tais como: agenda de atividades, termos de compromisso, crachá, planilha de custos e ficha de visitas.

O objetivo do lançamento do projeto no APL foi divulgá-lo, apresentar seus objetivos, equipe, parceiros e obter a adesão dos empresários.

Elaborou-se um diagnóstico empresarial do APL, que se restringiu ao nível operacional. As técnicas utilizadas para a coleta de dados foram: i) check list/questionário; ii) entrevista não estruturada; iii) observações in loco; e iv) análise de documentos. Depois da aplicação do diagnóstico, as informações coletadas foram tabuladas e analisadas pela equipe do projeto. O principal objetivo foi mapear as principais necessidades de melhorias das empresas e desenvolver propostas de ações.

Os resultados do diagnóstico foram apresentados individualmente para cada empresa por meio de um relatório de devolutiva, no qual constavam informações sobre as ações de melhorias prioritárias, os objetivos das ações, os resultados esperados e o cronograma de atividades.

\subsection{Fase 3 - Implantação e execução do plano de ações de melhoria contínua}

Para implantar as ações, foram selecionadas equipes de colaboradores das empresas que passaram a ser responsáveis pelos procedimentos de implantação, disseminação das informações, recebimento da equipe técnica para follow up e fornecimento de dados. As equipes foram compostas de quatro a cinco colaboradores selecionados pelos próprios empresários, sendo geralmente líderes de setores que detinham maiores conhecimentos na área de intervenção.

A próxima atividade foi realizar sensibilizações para os empresários, equipe e colaboradores nas empresas pela equipe técnica.

Depois disso, a equipe técnica conduziu uma seção de brainstorming juntamente com a equipe da empresa e empresários. A partir dos dados obtidos no brainstorming e no diagnóstico, a equipe técnica elaborou um plano de ação específico para cada empresa. O plano de ação foi apresentado na forma de $5 \mathrm{~W} 1 \mathrm{H}$. A equipe técnica acompanhou toda a implantação por meio de visitas semanais e quinzenais, com duração média de duas horas.

\subsection{Fase 4-Avaliação de resultados de desempenho}

O objetivo desta etapa foi avaliar as empresas e o APL antes e após o desenvolvimento do projeto. As perspectivas de desempenho utilizadas para avaliação foram: desempenho empresarial, impactos econômicos e sociais, eficiência coletiva e capital social (índice de cooperação).

Além de cumprir seu papel de ambientação dos pesquisadores permitindo-lhes vivenciar a realidade de um APL in loco, o estudo de caso também contribuiu com elementos que foram considerados na formulação 
das diretrizes apresentadas neste trabalho, modificando (validação) a versão preliminar advinda integralmente da teoria e permitindo a inclusão de novos elementos. Os principais elementos observados no estudo de caso que contribuíram mais diretamente para a elaboração das diretrizes estão sumarizados a seguir:

- Reuniões semanais com a equipe auxiliaram na troca de conhecimentos e informações;

- Parceria com atores locais tornou-se fundamental para a realização do projeto;

- Ferramentas simples utilizadas para coleta de dados, como check list, entrevista, observação e brainstorming, mostraram-se eficazes;

- Formação das equipes de trabalho nas empresas;

- Sensibilização das equipes de trabalho;

- Clareza na utilização do plano de ação com base no $5 \mathrm{~W} 1 \mathrm{H}$;

- Reformulação periódica do plano de ação; e

- Elaboração de medidas de desempenho alinhadas com as necessidades das empresas.

As principais dificuldades encontradas durante o processo de implantação de processos de melhoria contínua verificadas no estudo de caso foram:

- Pouca comunicação entre os setores internos das empresas;

- Pouca cooperação entre as empresas;

- Baixa qualificação dos funcionários na área de atuação do projeto;

- Inexistência de projetos anteriores que visassem à melhoria contínua de produtos e processos;

- Baixa integração entre os agentes locais e as empresas;
- Falta de indicadores para tomadas de decisões;

- Inexistência de uso das ferramentas básicas da qualidade; e

- Pouco controle de processos e planejamento estratégico.

Proposta de diretrizes para desenvolvimento coletivo de melhoria contínua em arranjos produtivos locais

A estruturação e apresentação das diretrizes foram feitas com base no ciclo PDCA, conforme se segue:

- P (plan): é composta pelas etapas de preparação, diagnóstico do APL e diagnóstico das empresas. Seu objetivo é obter dados sobre a realidade para implementar a proposta de melhoria contínua de forma customizada em forma de plano de ação;

- $\mathrm{D}(d o)$ : é composta pela etapa de implantação, cuja função é desenvolver o plano de ação e implementá-lo coletivamente;

- C (check): é composta pela etapa de auditoria. Sua função é analisar a evolução da implantação e gerar ações corretivas; e

- A (act): é composta pela etapa de avaliação dos indicadores, com o objetivo de consolidar as ações de melhorias e verificar novas necessidades. Assim, inicia-se um novo ciclo.

A proposta é composta por módulos (1 - preparação e diagnóstico do ambiente, 2 - implantação e auditoria do processo de melhoria, e 3 - avaliação de desempenho), que seguem o ciclo PDCA, subdivididos em etapas, conforme a Figura 2.

A síntese das diretrizes é a seguir apresentada:

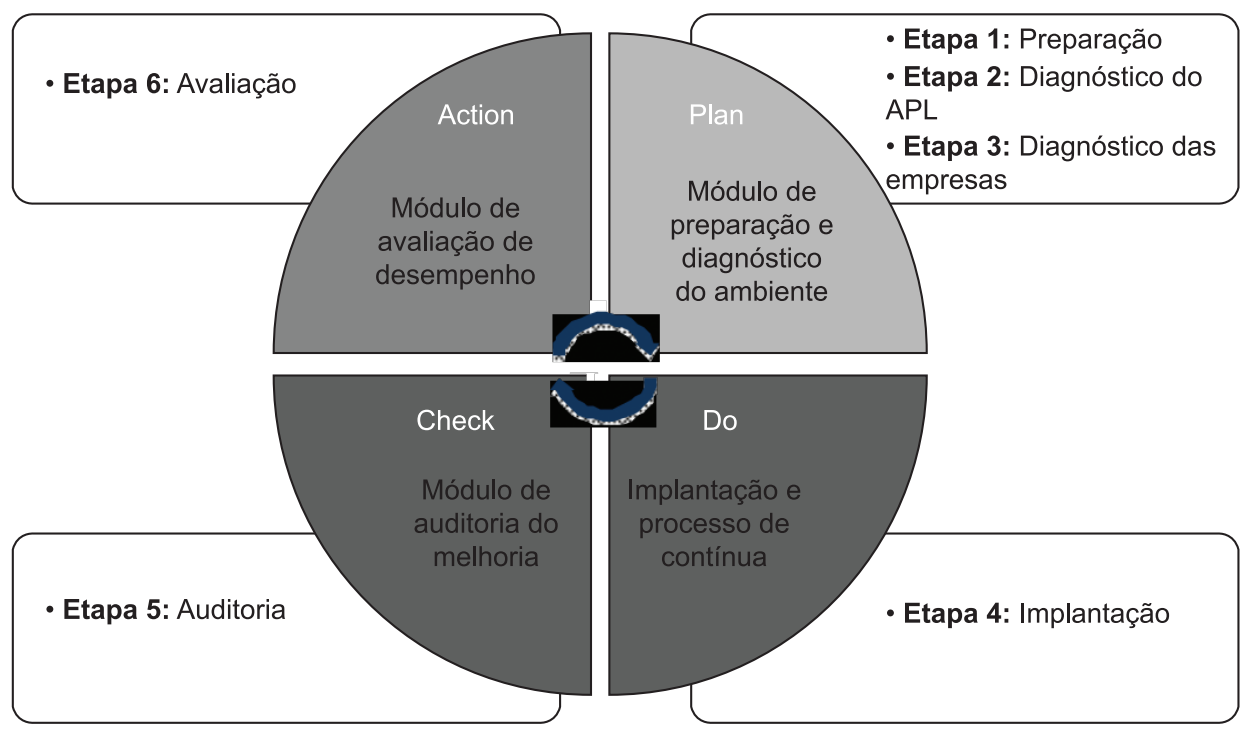

Figura 2. Proposta de diretrizes para desenvolvimento coletivo de melhoria contínua. 


\subsection{Etapa 1 - Preparação}

A primeira etapa envolve a preparação do ambiente para a implantação coletiva do processo de melhoria contínua e consiste no primeiro contato dos empresários com as diretrizes por meio de reunião direcionada por um grupo de coordenadores do processo de melhoria contínua do APL.

O grupo de coordenadores de melhoria contínua pode ser formado por:

- Coordenadores de projetos científicos de cooperação empresarial (universidades);

- União de grupos de empresários. Neste caso, pode haver contratação de profissionais qualificados para atender às necessidades e lacunas coletivas, como profissionais da área da qualidade, consultores especializados, entre outros; e

- Atores de governança local (associações, sindicatos, institutos de pesquisa e instituições de apoio).

A reunião deve ser divulgada pelo grupo de coordenadores de melhoria contínua para todos os empresários do APL. O principal objetivo é apresentar a proposta de diretrizes, sensibilizá-los e conscientizá-los, estimulando a confiança e esclarecendo dúvidas.

A parceria de empresários com o grupo de coordenadores deve ser documentada por um termo de compromisso, que deve ser assinado após a reunião de divulgação. Nesta reunião, deve ser definido o período previsto para implantação do programa de acordo com a necessidade e possibilidades das empresas e do APL.

Desta forma, deve ser desenvolvida uma agenda de planejamento das etapas de implantação, contendo informações tais como: tempo para executá-la, futuras sensibilizações e quem irá realizá-las.

\subsection{Etapa 2 - Diagnóstico do APL}

Esta etapa consiste no diagnóstico do APL, em que devem ser identificadas se já existem ações gerais de cooperação e em que nível, entre os empresários e os demais atores, e também se existem especificamente ações de melhoria contínua coletiva no APL.

O diagnóstico deve ser desenvolvido pelo grupo de coordenadores por meio de um check list $\mathrm{e}$ aplicado de forma coletiva, que pode ser respondido, por exemplo, pelo grupo de cooperação empresarial (empresários) durante uma reunião agendada.

Os dados coletados no check list devem ser tabulados pelo grupo de coordenadores e os resultados apresentados ao grupo de cooperação empresarial de forma coletiva, conscientizando-os quanto à importância de ações conjuntas para o desenvolvimento das empresas, do APL e do setor.

\subsection{Etapa 3 - Diagnóstico das empresas}

É necessário, antes da realização do diagnóstico propriamente dito nas empresas, a sua sensibilização. Devem ser formados times da qualidade em cada uma. A partir da sensibilização, o grupo de cooperação empresarial deve ser responsável por definir os funcionários que farão parte do time na sua empresa.

Desta forma, cada empresário deve realizar uma seleção com seus funcionários e comunicá-los sobre as diretrizes que serão implantadas, treinando-os em melhoria contínua, liderança, qualidade e esclarecendo a função do time. As pessoas selecionadas devem possuir características de liderança.

O passo seguinte será a formalização do processo e a elaboração do diagnóstico a ser aplicado nas empresas, para o qual o grupo de coordenadores deve desenvolver um check list, que tem a função de identificar em que estágio está cada empresa em relação à qualidade e à melhoria contínua.

A próxima reunião deve ser realizada com o grupo de cooperação empresarial e seus respectivos times, em que o check list será apresentado e respondido pelos grupos de cada empresa.

O empresário participante do grupo de cooperação empresarial e seu time devem realizar a sensibilização de seus funcionários, apresentando os objetivos das diretrizes de melhoria contínua e os principais conceitos e a importância da qualidade.

O time deve ser responsável por implantar, avaliar e disseminar conhecimento sobre o tema para todos os funcionários e o empresário deve ser responsável pelo acompanhamento do desempenho dos times.

Depois da coleta de dados, estes devem ser tabulados e analisados pelo grupo de coordenadores. Os resultados devem ser apresentados e discutidos com o grupo de cooperação empresarial e seus respectivos times em uma nova reunião. Assim, será possível definir as técnicas e ferramentas a serem desenvolvidas de acordo com as necessidades das empresas e o nível de melhoria contínua na qual se encontram.

\subsection{Etapa 4 - Implantação}

O grupo de coordenadores das diretrizes deve realizar um treinamento coletivo com os times, apresentando conceitos sobre as técnicas e ferramentas da qualidade a serem implantadas. Paralelamente, deve ser realizada uma sensibilização apresentando os conceitos sobre cultura organizacional e resistência à mudança, de forma a conscientizar o grupo de cooperação empresarial e os times sobre a importância em motivar e educar os funcionários.

Cada time deve realizar sensibilização junto aos funcionários de sua empresa, apresentando os conceitos e a importância da colaboração. Também devem conscientizá-los sobre a importância das 
mudanças advindas do processo de melhoria contínua. É importante promover a participação dos funcionários no processo de mudança e implantação por meio de treinamentos, palestras e reconhecimentos.

A próxima reunião será realizada para definir o plano de ação. Os times das empresas e o grupo de cooperação empresarial devem passar por uma seção de brainstorming conduzida pelo grupo de coordenadores. O objetivo da seção é levantar ideias, soluções, identificar barreiras e facilidades para a implantação das diretrizes.

Em seguida, o plano de ação deverá ser elaborado, de forma coletiva e simultânea por todos os integrantes do processo (times, empresários e grupo de coordenadores), a partir das informações do brainstorming e do questionário. As atividades do plano de ação podem ser elaboradas na forma de $5 \mathrm{~W} 1 \mathrm{H}$. Nesta etapa, devem ser definidos os indicadores para avaliar o desempenho da implantação.

A partir do resultado do questionário e das atividades de implantação, deve ser elaborado um sistema de medição de desempenho (indicadores) coletivo que servirá para análise dos resultados. Este sistema deve ser aprovado pelo grupo de cooperação empresarial e ser desenvolvido de forma a atender às necessidades conjuntas das empresas e do APL. Os dados devem ser coletados antes, durante e após a implantação por uma equipe treinada, que pode ser o time da qualidade.

\subsection{Etapa 5 - Auditoria}

Depois do período previsto para implantação de cada atividade do plano de ação, devem ser realizadas reuniões coletivas para apresentação e acompanhamento do projeto. Cada empresa deve expor os resultados (auditorias), as dificuldades e os benefícios alcançados. Durante as reuniões o plano de ação poderá ser reformulado e melhorado para cada atividade prevista.

A periodicidade destas reuniões pode ser definida de acordo com as necessidades do grupo de cooperação empresarial, sendo de extrema importância para a troca de conhecimentos, informações, planejamentos e cooperação.

Os resultados das auditorias devem ser apresentados para todos os funcionários das empresas pelo empresário e seu time, bem como os novos passos a serem seguidos e o papel das pessoas para alcançar as metas estabelecidas.

\subsection{Etapa 6 - Avaliação}

Consiste na avaliação de desempenho do desenvolvimento coletivo do processo de melhoria contínua no APL por meio de coleta de dados. Para isto é importante incentivar a revisão periódica dos indicadores e, caso necessário, fazer reformulações.

Nesta fase devem participar ativamente o grupo de cooperação empresarial, seus times e o grupo de coordenadores das diretrizes de melhoria contínua do APL. Deve-se avaliar se a estratégia de implantação trouxe benefícios para as empresas e se as necessidades e expectativas foram atendidas. Desta forma, será possível consolidar a melhoria.

Torna-se importante apresentar um feedback do resultado da avaliação para todos os funcionários das empresas, e cada empresário e seu time devem discutir os dados pertinentes. Depois da avaliação, a próxima atividade deve ser a análise de novas necessidades e dar continuidade à proposta de melhoria contínua. Desta forma, torna-se fundamental padronizar as etapas e atividades implantadas, gerando um aprendizado contínuo para realimentar a proposta de melhoria contínua.

\section{Conclusão}

A melhoria contínua pode ser um grande impulso ao desenvolvimento e aumento da competitividade de grupos de MPMEs organizados em APLs. Mas sua implantação requer uma nova forma de pensar e agir por parte dos empresários, em que as mudanças devem estar alinhadas à cultura das empresas e contemplar o envolvimento dos funcionários.

As diretrizes aqui propostas foram elaboradas com base no referencial teórico e são uma evolução de trabalhos correlatos estudados a partir de sua adaptação, fusão e melhoria. Um estudo de caso foi realizado com a função de familiarizar os pesquisadores com um exemplo da realidade estudada de forma a dotar a proposta de maior grau de exequibilidade e também com a função de aprimorá-la.

Acredita-se que estas diretrizes são uma contribuição real e efetiva para o estado da arte (contribuição acadêmica) no sentido que considerou importantes trabalhos científicos e os incorporou. Também se acredita que elas são uma factual contribuição ao mercado tendo em vista que orienta e sugere métodos e procedimentos para o desenvolvimento da melhoria contínua em MPMEs que atuam em APLs.

Como principal limitação deste trabalho tem-se a necessidade da implantação, em sua versão final, das diretrizes aqui propostas em APLs para verificar a necessidade de ajustes, visando aumentar seu grau de generalização. Espera-se, no entanto, que isto possa ser realizado por esta equipe de autores e outros profissionais e acadêmicos a curto e médio prazos.

\section{Agradecimentos}

Agradecemos ao CNPq e à Fundação Araucária terem financiado a realização desta pesquisa. 


\section{Referências}

AMURA, A. B. G. F.; CUPERSCHMID, A. R. M.; PEREIRA, T. R. D. S. Técnicas de dinâmicas de grupo no ensino de engenharia de produção. In: SIMPÓSIO DE ENGENHARIA DE PRODUÇÃO, Bauru. Anais... Bauru, 2008.

AMATO NETO, J. Gestão de sistemas locais de produção e inovação (clusters/APL): um modelo de referência. São Paulo: Atlas, 2009.

BELUSSI, F.; ARCANGELI, F. A Typology of networks: flexible and evolutionary firms. Research Policy, v. 27, n. 4, p. 415-428, 1998. http://dx.doi.org/10.1016/ S0048-7333(98)00074-2

BESSANT, J.; CAFFYN, S.; GALLAGHER, M. An evolutionary model of continuous improvement behavior. Technovation, v. 21, n. 1, p. 67-77, 2001. http://dx.doi. org/10.1016/S0166-4972(00)00023-7

BRASIL. Ministério do Desenvolvimento, Indústria e Comércio Exterior - MDIC. Termo de referência para política nacional de apoio ao desenvolvimento de Arranjos Produtivos Locais. MDIC, 2004. Disponível em: <http://www.mdic.gov.br/arquivos/ dwnl_1289322946.pdf>. Acesso em: 20 jan. 2011.

BUENO, A. M. Arranjos produtivos locais: análise da caracterização do APL de Ponta Grossa com base nos indicadores. 2006. Dissertação (Mestrado em Engenharia de Produção)-Universidade Tecnológica Federal do Paraná, Ponta Grossa, 2006.

CAFFYN, S. Development of a continuous improvement selfassessment tool. International Journal of Operations and Production Management, v. 19, n.11, p.1138-1153, 1999. http://dx.doi.org/10.1108/01443579910291050

CARNEVALLI, J. A.; MIGUEL, P. A. C. Revisão, análise e classificação da literatura sobre o QFD: tipos de pesquisa, dificuldades de uso e benefícios do método. Gestão $\boldsymbol{\&}$ Produção, v. 14, n. 3, p. 577-579, 2007.

CARPINETTI, L. C. R. Gestão da melhoria de aglomerados industriais: identificação de necessidades e formas de atuação conjunta. 2005. Projeto de Pesquisa.

CASSIOLATO, J. E.; LASTRES, M. H. O foco em arranjos produtivos e inovativos locais de micro e pequenas empresas. In: LASTRES, H. M.; CASSIOLATO, J. E.; MACIEL, M. L. (Orgs.). Pequena empresa: cooperação e desenvolvimento local. Rio de Janeiro: Relume Dumará, 2003. p. 21-34.

DAIBERT, J.; FISCHER, R. União, Planejamento e Sucesso. Revista ACIM, n. 475, p. 10-13, 2008.

DEPEXE, M. D.; PALADINI, E. P. Benefícios da implantação e certificação de sistemas de gestão da qualidade em empresas construtoras. Gestão Industrial, v. 4, n. 2, p. 145-161, 2008.

FERNANDES, J. M. R.; REBELATO, M. G. Proposta de um método para integração entre QFD e FMEA. Gestão \& Produção, v. 13, n. 2, p. 245-259, 2006. http://dx.doi.org/10.1590/S0104-530X2006000200007

GALDAMEZ, E. V. C. Proposta de um sistema de medição de desempenho para clusters industriais de pequenas e médias empresas. 2007. Tese (Doutorado em Engenharia de Produção)-Escola de Engenharia de São Carlos, Universidade de São Paulo, São Carlos, 2007.
GAPP, R.; FISHER, R.; KOBAYASHI, K. Implementing $5 S$ within a Japanese context: an integrated management system. Management Decision, v. 46, n. 4, p. 565-579, 2008. http://dx.doi.org/10.1108/00251740810865067

GEROLAMO, M. C. Proposta de sistematização para o processo de melhorias e mudanças de desempenho. 2003. Dissertação (Mestrado em Engenharia de Produção)-Escola de Engenharia de São Carlos, Universidade de São Paulo, São Carlos, 2003.

HYDE, K. F. Recognizing deductive processes in qualitative research. Qualitative Market Research: An International Journal, v. 3, n. 2, p. 82-90, 2000. http://dx.doi.org/10.1108/13522750010322089

JACOBSEN, A. L.; RODRIGUES, M. M. B. Abordagens para lidar com a resistência humana frente a processos de mudança organizacional. Revista de Ciências da Administração, v. 4, n. 6, p. 39-49, 2002.

JAGER, B. et al. Enabling continuous improvement: a case study of implementation. Journal of Manufacturing Technology Management, v. 15, n. 4, p. 315-324, 2004. http://dx.doi.org/10.1108/17410380410535017

KARAEV, A.; KOH, S. C. L.; SZAMOSI, L. T. The cluster approach and SME competitiveness: a review. Journal of Manufacturing Technology Management, v. 18, n. 7, p. 818-835, 2007. http:// dx.doi.org/10.1108/17410380710817273

KATZENBACH, A. H.; SMITH, D. K. The discipline of teams. Harvard Business Review, 1993.

LIN, C. C.; LUH, D. B. A vision-oriented approach for innovative product design. Advanced Engineering Informatics, v. 23, n. 2, p. 191-200, 2009. http://dx.doi. org/10.1016/j.aei.2008.10.005

MARTINS, P. G.; LAUGENI, F. P. Administração da Produção. 2. ed. São Paulo: Saraiva, 2005.

MESQUITA, M.; ALLIPRANDINI, D. H. Competências essenciais para melhoria contínua da produção: estudo de caso em empresas da indústria de auto-peças. Gestão \& Produção, v. 10, n. 1, p. 17-33, 2003. http://dx.doi. org/10.1590/S0104-530X2003000100003

MIGUEL, P. A. C. Qualidade: enfoques e ferramentas. São Paulo: Artiber, 2001.

MIGUEL, P. A. C. Estudo de caso na engenharia de produção: estruturação e recomendações para sua condução. Produção, v. 17, n. 1, p. 216-229, 2007.

NUNES, C. E. C. B.; ALVES, I. B. S. Implantação do programa $5 \mathrm{~s}$ no departamento pessoal de uma empresa de segurança privada (estudo de caso). In: ENCONTRO NACIONAL DE ENGENHARIA DE PRODUÇÃO, 28., Rio de Janeiro. Anais... Rio de Janeiro, 2008.

OBADIA, I. J.; VIDAL, M. C. R.; MELO, P. F. F. Uma abordagem adaptativa de intervenção para mudança organizacional. Gestão \& Produção, v. 14, n. 1, p. 125-138, 2007. http://dx.doi.org/10.1590/ S0104-530X2007000100011

OLIVEIRA, O. J. Gestão da qualidade: introdução à história e fundamentos. In: OLIVEIRA, O. J. (Org.). Gestão da qualidade: tópicos avançados. São Paulo: Pioneira Thomson Learning, 2004.

OLIVEIRA, O. J. Pequena empresa no Brasil: um estudo de suas características e perspectivas. Integração, v. 11, p. 5-15, 2006. 
OLIVEIRA, O. J. Gestão da qualidade e produtividade na logística. Curitiba: IESD; 2009.

OSBORN, A. F. O poder criador da mente: princípios e processos do pensamento criador e do brainstorming. 7. ed. São Paulo: IBRASA, 1991.

PALADINI, E. P. Gestão da qualidade: teoria e prática. São Paulo: Atlas, 2004.

PINHEIRO, C. R. M. S. Práticas para implantação de sistemas de gestão ambiental certificáveis: um enfoque na gestão de pessoas. 2009. Dissertação (Mestrado em Engenharia de Produção)-Faculdade de Engenharia de Bauru, Universidade Estadual Paulista, Bauru, 2009.

PORTER, M. E. Competição: estratégias competitivas essenciais. 5. ed. Rio de Janeiro: Campus, 1999.

REDE PARANAENSE DE APOIO AOS ARRANJOS PRODUTIVOS LOCAIS - REDE APL. Rede paranaense de apoio aos arranjos produtivos locais: APL de confecções de Cianorte e Maringá - PR. Disponível em: <www.redeapl.pr.gov.br>. Acesso em: 13 fev. 2010.

RODRIGUES, A. M. Ações de melhoria na manufatura: investigação dos mecanismos de geração e abordagens utilizadas - estudo de caso em empresas de autopeças.1998. Dissertação (Mestrado em Engenharia de Produção e Sistemas)-Universidade Federal de São Carlos, São Carlos, 1998.

SANTOS, J. A. Estudo sobre a questão da mudança e da resistência à mudança nas organizações. Revista de Ciências Gerenciais, v. 9, n. 11, 2005.

SANTOS, N. M. B. F. Cultura e desempenho organizacional: um estudo cultura e desempenho organizacional: um estudo empírico em empresas brasileiras do setor têxtil. Revista de Administração Contemporânea, v. 2, n. 1, p. 47-66, 1998.

SCHMITZ, H. Collective efficiency: growth path for small-scale industry. The Journal of Development Studies, v. 31, n. 4, p. 529-566, 1995. http://dx.doi. org/10.1080/00220389508422377

SCHOLTES, P. R. Times da qualidade: como usar equipes para melhorar a qualidade. Rio de Janeiro: Qualitymark, 1992.

SILVA, N. B. Os programas de melhoria contínua como processos de aprendizagem organizacional: o caso de uma indústria de produtos alimentícios. 2003. Dissertação (Mestrado em Administração)-Faculdade de Economia, Administração e Contabilidade, Universidade de São Paulo, São Paulo, 2003.

SIMÕES, R.; ALLIPRANDINI, D. H. Gestão da melhoria contínua: modelo de boas práticas e aplicação em uma empresa de médio porte. In: ENCONTRO NACIONAL DE ENGENHARIA DE PRODUÇÃO, 26., Fortaleza. Anais... Fortaleza, 2006.

SINDICATO DA INDÚSTRIA DO VESTUÁRIO DE MARINGÁ - SINDVEST. Disponível em: <www. sindvest.com.br>. Acesso em: 05 dez. 2009.

SOUSA, M. Q. L.; CAMPOS, A. C. C. F.; RAMOS, R. E. B. Trabalho em equipe: a base da qualidade nas organizações. In: CONGRESSO BRASILEIRA DE EDUCAÇÃO EM ENGENHARIA, 38., Fortaleza. Anais... Fortaleza, 2008.

STORPER, M.; HARRISON, B. Flexibility, hierarchy an regional development: the changing structure of industrial production systems and their forms of governance in the 1990s. Research Policy, v. 20, n. 5, p. 407-422, 1991. http://dx.doi.org/10.1016/0048-7333(91)90066-Y

SUZIGAN, W.; GARCIA, R.; FURTADO, J. Estruturas de governança em arranjos ou sistemas locais de produção. Gestão \& Produção, v. 14, n. 2, p. 425-439, 2007. http://dx.doi.org/10.1590/S0104-530X2007000200017

TORELLI, L. C.; FERREIRA, J. J. A. Qualidade total: proposta de um modelo para implantação. Gestão \& Produção, v. 2, n. 3, 1995.

VIEIRA, A. M. Proposta de diretrizes para o desenvolvimento coletivo de melhoria contínua em micro, pequenas e médias empresas de arranjo produtivo locais. 2011. Dissertação (Mestrado em Engenharia de Produção)Universidade Estadual Paulista, Bauru, 2011.

VILLELA, L. E.; PINTO, M. C. S. Governança e gestão social em redes empresariais: análise de três arranjos produtivos locais (APLs) de confecções no estado do Rio de Janeiro. Revista de Administração Pública, v. 43, n. 5, 2009.

ZACCARELLI, S. B. Estratégia e sucesso nas empresas. São Paulo: Saraiva, 2000.

ZAMPINI, C. S.; TOLEDO, J. C. Proposta para estruturação da gestão da melhoria contínua em uma fabricante de bebidas. In: SIMPÓSIO ACADÊMICO DE ENGENHARIA DE PRODUÇÃO, 4., Viçosa. Anais.. Viçosa, 2008.

YIN, R. K. Estudo de caso: planejamento e métodos. 4. ed. Porto Alegre: Bookman, 2010.

$\mathrm{ZU}, \mathrm{X}$. Infrastructure and core quality management practices: how do they affect quality? International Journal of Quality \& Reliability Management, v. 26 n. 2, p.129149, 2009. http://dx.doi.org/10.1108/02656710910928789 